le portiQue $\begin{array}{ll}\text { Le Portique } \\ \text { Revue de philosophie et de sciences humaines }\end{array}$

$30 \mid 2013$

Écrire sur l'art

\title{
Présentation
}

\section{Roland Huesca}

\section{OpenEdition}

\section{Journals}

\section{Édition électronique}

URL : http://journals.openedition.org/leportique/2631

DOI : 10.4000/leportique.2631

ISSN : $1777-5280$

\section{Éditeur}

Association "Les Amis du Portique"

\section{Édition imprimée}

Date de publication : 18 juillet 2013

ISSN : 1283-8594

\section{Référence électronique}

Roland Huesca, «Présentation », Le Portique [En ligne], 30 | 2013, mis en ligne le 18 juillet 2013, consulté le 26 mars 2021. URL : http://journals.openedition.org/leportique/2631 ; DOI : https://doi.org/ 10.4000/leportique.2631

Ce document a été généré automatiquement le 26 mars 2021.

Tous droits réservés 


\title{
Présentation
}

\author{
Roland Huesca
}

1 Ce numéro du Portique est issu, en partie, d'un séminaire de recherche intitulé : écrire sur l'art aujourd'hui animée par Roland Huesca au sein de l'axe "Arts et Industrie culturelle » du Laboratoire Lorrain de Sciences Sociales. La motivation première était de partir d'un article ou d'un ouvrage afin d'entrer dans l'intimité des processus de la pensée. Puis, l'idée est venue d'élargir la problématique. Car écrire sur l'art, c'est fouiller une multitude de rapports : rapport aux œuvres bien sûr, mais aussi à soi et aux autres. En invitant, d'une part architecture, littérature, cinéma, danse, opérette, arts plastiques ou encore photographie, et d'autre part, philosophie, histoire, sociologie et esthétique, ce recueil de texte ne veut pas mélanger les genres ni confondre les points de vue. Il tente simplement de caractériser différents moments qui sont autant de modes d'existence du chercheur ou de l'artiste engagé dans sa tâche. Apparaissent ainsi plusieurs gestes tramés dans des espaces et des temps différents, mais soutenus par un même effort existentiel : se lover dans l'écriture pour témoigner d'une façon de faire et révéler une manière d'être.

2 L'écrit : une conscience et une conquête de soi. Que l'on aborde l'analyse des Confessions de Rousseau ou celle des Salons de Diderot, le rapport à l'écrit relève d'une herméneutique de soi singulière. Analysant le surgissement dans l'écriture d'un monument - le pont du Gard - Benoît Goetz révèle la part de soi impliquée dans la lecture de l'œuvre et, à travers elle, la part des autres inscrite en soi. De son côté, Gilles Gourbin, décryptant chez Diderot un mouvement scriptural où le "rendre compte" se déploie dans un "rendre conte ", dévoile la dynamique incessante que l'auteur entretient de soi à soi et de soi à sa pensée.

3 La légitimité des cadres de l'écriture. Pour écrire sur l'art, il faut que l'objet d'étude soit perçu comme relevant du domaine artistique! L'exemple de la photographie est sur ce point probant. Montrant les mutations des regards posés sur la photographie et sur l'art lui-même, Patrick Talbot construit l'histoire de ces dédales. Dans le même temps, analysant l'effort de légitimation intellectuelle exigible du chercheur qui s'implique personnellement dans un divertissement artistique de masse: le cinéma, Jean-Marc 
Leveratto étudie les contraintes qui pèsent sur la production des discours sociologiques sur l'art.

Dans les coulisses de l'écrit. Écrire, c'est une attitude, une histoire de gestes et de postures de la pensée. Dans son essai d'épistémologie pratique, Jean-Claude Yon en dessine les traits sous les formes d'un bestiaire où engagement, labeur, habileté et raison jouent de concert. "Je me sers d'animaux pour instruire les hommes», disait La Fontaine: désormais, voici malicieusement ces figures au service d'une méthode de travail! Pour sa part, Roland Huesca s'interroge sur la manière dont peuvent interagir l'intelligibilité narrative et l'intelligibilité explicative. Loin d'être accessoire, l'acte d'écrire ne se borne pas à donner un habillage linguistique venant accoutrer une intelligence du passé déjà constituée avant de "s'encrer" dans une configuration littéraire. Si dans son élaboration, la narration doit assumer un style et une singularité, elle reste surtout un instrument de pensée. Creusant une même veine, Hélène Guénin et Guillaume Désanges retracent le processus créateur de l'exposition Erre - Variations labyrinthiques présentée au Centre Pompidou-Metz du 12 septembre 2011 au 5 mars 2012. Sous la forme du schéma qui fut le carnet de bord de cette aventure, ils développent quelques-uns des principes qui auront prévalu dans les différentes étapes de la construction. Ils soulignent l'interaction permanente entre des engagements forts et des règles d'incertitude et de doute, des positions éthiques et les élans de l'intuition, la raison et la séduction, la sophistication et le bricolage.

5 L'écriture comme médium et média. Écrire, c'est aussi proposer aux œuvres de nouvelles formes d'existence. Claire Lahuerta le démontre en analysant les défis d'une "scénographie plasticienne" qui, transformant la relation œuvre/spectateur, encourage la multiplication des points de vue. Dans le domaine des arts plastiques et visuels, ces usages renouvelés de l'exposition deviennent alors autant « écriture » d'un dispositif que « lecture » de celui-ci. Lecture encore, mais sous forme de catalogue cette fois. C'est ce que relate Laurent Le Bon, le directeur du Centre Pompidou-Metz, en dévoilant au cours d'un entretien l'histoire, les atours et les enjeux de la réalisation de plusieurs catalogues d'expositions présentées à Paris et à Metz. 